DOI 10.37882/2223-2982.2021.08.07

\title{
К ВОПРОСУ О БАЗОВЫХ ХАРАКТЕРИСТИКАХ ФРАЗЕОСЕМАНТИЧЕСКИХ ПОЛЕЙ
}

\section{ON THE QUESTION OF THE BASIC CHARACTERISTICS OF PHRASEOSEMANTIC FIELDS}

\section{A. Goncharova}

Summary: New phraseological units, connected with the help of special types of the semantic relationship, are analyzed in the article. They are called "phraseological fields or microidioms». The complicated cases of structuring these units and the ways of their expressing in the contexts are also paid attention to. There are special limited borders of their functioning and existing in the languages, which have been researched in the article.

Keywords: microidioms, phraseosemantic fields, contextual situations, limited idiom borders, basic and secondary microidiom characteristics.
Гончарова Алена Владимировна

К.филол.н., дочент, Российская Академия народного хозяйства и государственной службы при Президенте РФ,

Москва

litera2306@mail.ru

Аннотация: В статье анализируются определенные новообразования фразеологических полей, связанные устойчивыми типами семантических отношений, которые получили название «фразеосемантические поля». Рассмотрены сложные моменты структурирования этих языковых единиц, их способы выражения в ряде ситуативных контекстов. Проанализированы некоторые ограничительные рамки, связанные с существованием микроидиом, и представлены выводы по факту их возникновения и существования в языках.

Ключевые слова: микроидиомы, фразеосемантические поля, ситуативные контексты, ограничительные рамки идиом, базовые и периферийные характеристики микроидиом.

В зарубежной лингвистике большой интерес к рассмотрению корреляционных схем идиом через призму теории изоморфизма проявился в Британской лингвистической Школе Кембриджского Университета в 90-х годах 20 века. Значительное количество летних школ по изучению английского языка при университете столкнулось с проблемой объяснения семантики фразеологизмов иностранным учащимся.

Дуальность значений многих идиом создавала сложности не только в соответствующем их использовании, но и в объяснении контекстуальных связей. Преподаватели начали использовать систему Рахмана для правильной подачи материала по фразеологизмам. Методика Рахмана состоит в предоставлении учащимся всех возможных контекстуальных комбинаций конкретных идиом без дополнительных объяснений преподавателем их значений [16. с.29].

Упор делался на индивидуальную перцепцию ученика. Методика Рахмана популярна до сих пор и лежит в основе обучения устной речи и грамматике всех летних языковых школ при Кембриджском Университете.

Для организационной структуры поля разных языковых систем характерны специфические отношения. Например, отношения синонимии, антонимии для лексики и фразеологии.

Задачей данной работы является анализ фразеологизмов через призму базовых характеристик семантических полей на материале произведения М. Горького 
«Детство» [9. с.129].

Из общей базы фразеологических единиц можно выделить более узкие семантические группы. Общность логических бытовых сфер в разных языках соответственно создают аналогичный круг фразеологических явлений.

Теории семантических полей в современной отечественной и зарубежной лингвистике разрабатывались, главным образом, с опорой на лексемы. И здесь возникает вопрос о соотношении лексического и фразеологического полей.

Вопрос о правомерности объединения лексики и грамматики одинаковой понятийной соотнесенности в одно или о проблеме сосуществования параллельных фразеологических и лексических полей решаются неоднозначно.

Встает вопрос о релевантных лингвистических и экстралингвистических критериях, используемых при сопоставлении лексем и других единиц языка.

Ряд лингвистов трактует фразеосемантическое поле как компонент общего лексико-семантического поля. Архангельская И.Л. [2. с.57], Алехина А.И.[3. с.79], Лейкина Д.Д.[13. с.28].

Другие языковеды анализируют фразеосемантическое поле как отдельную самостоятельную систему. Дашевская В.Л.[10. с.29], Черная А.И. [17. с.85] Коган О.С [12. С.57], Бонч А.П. [7. с.26].

Мы полагаем, что подобные различия в трактовке фразеосемантического поля восходят к разному пониманию уровней стратификации языка. Также, зависят от упора на общие или различные черты между лексическими и фразеологическими единицами.

Мы придерживаемся мнения, что функциональная и семантическая соотнесенность части лексики и фразеологии, проявляющаяся в ряде черт, делает реальным построение единого лексико-фразеологического семантического поля. Доказательством этому может служить, в частности, общность параметров, характеризующих любое семантическое поле, а именно - принцип выделения поля, его структурная организация, парадигматические отношения конституантов, отношение поля как системы к аналогичным системам и т.д.

Семантическое поле охватывает явления разных уровней, объединенных единым значением и выражающихся в этом значении в определенной понятийной категории. В этом случае лексико - фразеологическое поле может рассматриваться как часть макрополя, объединяющее единицы разных уровней языка. Поэтому представляется правомерным рассматривать фразеологиз- мы как микрополе со своими специфическими чертами.

Фразеологизм может передавать не только расчлененные представления об отдельных признаках свойствах и явлениях, но и расчлененные представления о предметах и их характеристиках о процессах и их признаках, об отношении действия к объекту о ситуации.

Фразеологическое значение строится на соотношении денотативного плана и коннотативного плана. Значение это отличается от аналогичного соотношения в лексеме. Для фразеологизмов характерен отрыв от денотата и возможность изменения денотативной соотнесенности. Понятийное содержание передается всем комплексом компонентов.

При построении семантического поля ученые обычно опираются на ономасиологический критерий, когда решающую роль играет денотативный фактор. Это означает, что поле рассматривается через призму соответствующего участка действительности, и степень системности поля оказывается зависимой от степени системности объективного мира.

Однако фразеологизм связан не только с внешним миром, но и с субъективным моментом, поскольку при помощи фразеологизмов человек называет предмет и выражает свое отношение, оценивает различные явления с разных сторон. Отсюда понятна значимость исследования обеих сторон содержательного потенциала языковых единиц, который может быть и логико-предметным и эмотивным. Поэтому при вычленении семантических полей актуальным является исследование разных факторов, включая и экспрессивно - оценочные.

Можно сказать, что с точки зрения организации семантическое поле имеет двуединое основание. Его денотативная часть связывает поле с определенным участком действительности, с миром природы и явлений. Оценочная часть этого основания тяготеет к субъекту, к выражению его состояния и отношения к внешнему миру. Таким образом, организация семантического поля рассматривается с учетом коммуникативных представлений.

В этом смысле фразеологизмы представляют собой и средство познания окружающего мира, и средство коммуникации, и способ выражения субъективного отношения индивида к предмету высказывания. То есть фразеологизм является средством эмоционального воздействия на слушателя.

Коммуникативный подход означает, что необходимо изучать смысловое содержание и форму фразеологизма в процессе его взаимодействия со смысловой структурой речевых единиц, находящихся в каких-либо отношениях с фразеологизмом. 
Ориентирование на коммуникативный подход связано еще и с тем, что фразеологизм, даже в изолированном от контекста виде, часто несет на себе отпечаток потенциального речевого акта и рассматривается через призму планируемой коммуникативной установки, являясь своеобразной «заготовкой» для конкретной коммуникативной ситуации.

Важную роль при этом играет субъект, не всегда совпадающий с грамматическим понятием «подлежащее». Субъект - это имплицируемое лицо социально - обобщенного характера. Именно на субъекте сосредоточена эмоциональная сторона высказывания.

Интерес лингвистов к проблемам оценочной семантики существует уже довольно давно - Арнгольц В.О.[5.с.60], Дубовец Е.П.[11.с.38], Бони П.П.[8.с.43] .

В оценочной семантике они видят не случайное, а закономерное следствие познавательной деятельности и взаимодействия человека с окружающим миром. Предметы и явления, общественные отношения выступают не только как объекты познавательной деятельности, но и как объекты эмоциональных оценок. Субъектом оценки является лицо или социум, с точки зрения которого дается оценка.

И субъект, и объект оценки предполагают существование субъективного и объективного факторов, взаимодействующих друг с другом.

Субъект, оценивая предметы и события, опирается с одной стороны, на свое отношение к объекту оценки, а с другой стороны - на стереотипные представления об объекте и шкалу оценок, на которой расположены присущие объекту признаки. В оценочном объекте, в свою очередь, также сочетаются субъективные и объективные признаки.

Все вышеперечисленное необходимо учитывать при создании фразеосемантического поля и при распределении в нем микроидиом - фразеологических единиц, в состав которых входит не более чем один знаменательный компонент. Такое поле - «микроидиоматика» является составной частью фразеологии. Особенный интерес представляют собой участки семантических полей, закрытых микроидиомами.

Исследование данной статьи проводилось с позиций субъекта, принимая во внимание коммуникативный подход к анализу микроидиом. Учитывалось фразеологическое значение и назначение самой идиомы в речевом акте.

При помещении микроидиомы в то или иное поле решающее значение имел ответ на вопрос: с какой целью говорящий использует данную единицу?
Мы исходили из того, что фразеологические единицы вообще, и микроидиомы, в частности, в большинстве своем предназначены для выражения оценки.

Это означает, что в них можно выделить такой компонент как оценочность или эмотивность.

Этот термин не связан с представлениями об эмоциях экспрессивности, но может подразумевать как рациональную, так и эмоциональную оценку. Подобное разделение чисто рационального и чисто эмоционального в языке является условным. Тем не менее, способы выражения двух видов оценки в языке различаются, показывая, какое начало лежит в основе суждения о ценности объекта - эмоциональное или рациональное.

Нам бы хотелось подчеркнуть наличие оценочности в микроидиомах. Именно поэтому в название полей включено слово «характеристика», ведь когда мы даем характеристику кому - или чему - либо, мы, так или иначе оцениваем человека предмет или их свойств.

В результате проведенного анализа текста произведения М. Горького «Детство» можно сделать следующие выводы. Проанализированный материал доказал, что в силу специфики своей системы фразеологизмы охватывают, в первую очередь, сферу переживаний, чувств, психофизиологических состояний и сферу явлений и процессов объективной действительности, которые в большой степени способствует появлению модальнооценочных характеристик.

Результатом анализа значений микроидиом и их коммуникативной ориентированности стало объединение их в следующие основные семантические поля:

1. Характеристика человека;

2. Характеристика состояния человека;

3. Характеристика отношений между людьми;

4. Характеристика эмоциональных проявлений;

5. Характеристика предмета;

6. Характеристика пространства;

7. Характеристика времени;

8. Характеристика степени;

9. Характеристика действия.

Внутри семантического поля выделяются основные микрополя, объединяющие фразеологизмы по тому или иному признаку. Например, в поле «характеристика человека» выделены микрополя:

1. Характеристика финансового положения» - при деньгах, без гроша;

2. Характеристика человека в обществе» - на побегушках, вне закона;

3. «Характеристика умственных способностей»- с головой, с дурью;

4. «Характеристика физических особенностей»- в теле, как доска; 
5. «Характеристика отношения к делу» - до лампочки, не по зубам;

6. «Личностные характеристики человека» - по природе, не из таких;

Микрополя неодинаковы по объему. Некоторые фразеологизмы могут входить в несколько микрополей.

Фразеосемантические поля не изолированы друг от друга. Существуют опосредствованные, семантические звенья и их цепочки, позволяющие попадать из одного микрополя в другое в пределах одного семантического поля. Вышесказанное относится, в первую очередь, к многозначным фразеологизмам, которые делегируют свои значения в разные семантические микрополя.
У микроидиом «в долгу, в душе, хоть бы хны» разные значения входят в разные поля - «характеристика человека» и «характеристика состояния человека». «Он был в долгу у Аникеева и потому боялся встречи с ним» и «Он в долгу перед женой - она спасла ему жизнь».

Представляется интересным проанализировать большее сочетание микроидиом не только в русском, но и в английском языках. При их анализе и сопоставлении становятся явными значительные релевантные и нерелевантные признаки распределения микроидиом по разным фразеосемантическим полям в зависимости от семантической наполняемости самих идиом и от окружающего их контекста. Эта тема представляет собой большой интерес для последующих исследований языковых семантических полей.

\section{ЛИТЕРАТУРА}

1. Аверпэ П.О. Комплексные параллели фразеологизмов в языках разных систем. Эстония Тартусский Университет. Записки факультета лингвистики. Вып.18. Тарту. 2018

2. Архангельская И.Л. Семантические и структурные связи идиоматических выражений. Сборник научных статей Вильнюсского Университета. «Филология и педагогика». Вып.23. Вильнюс. 2019

3. Алехина А.И. К вопросу о контекстуальных параметрах использования фразеологизмов. Научные записки филологического ф-та Псковского Государственного Университета. Вып.5. Псков. 2019

4. Ахониади П.Н. Греческие идиомы ы современной речи. Сборник научных статей филологического ф-та Дальневосточного Государственного Университета. Серия Наука России. Вып. 17. 2019

5. Арнгольц В.О. Семантические лакуны как основа существования фразеологизмов. Эстония. Тартусский Университет. Записки факультета лингвистики. Вып.23.Тарту. 2019

6. Бернштейн Г.М. Еще раз о факте существования идиом. Сборник научных статей Вильнюсского Университета. «Филология и педагогика». Вып.26. Вильнюс. 2020

7. Бонч А.П. Структурные корреляции языковых застывших словосочетаний. Научные записки филологического ф-та Псковского Государственного Университета. Вып.б. Псков. 2019

8. Бони П.П. Фразеологизмы и пословицы как неделимая часть языкового фонда. Сборник научных статей филологического ф-та Дальневосточного Государственного Университета. Серия «Наука России». Вып.19. 2019

9. Горький М. «Детство». Москва. Издат-во Лань. Серия «Художественная литература». 2018.

10. Дашевская В.Л. Пословицы и поговорки в современных славянских языках. Сборник научных статей Минского Государственного Педагогического Университета. Серия «Молодые ученые». Вып.11. Минск. 2020

11. Дубовец Е.П. Славяноведение и идиомоведение. Научные записки факультета педагогики и психологии Минского Государственного Педагогического Университета. Серия « Молодые ученые». Вып.14. 2020

12. Коган 0.С. Еще раз о типах фразеологизмов. Научные записки факультета педагогики и психологии Минского Государственного Педагогического Университета. Серия «Молодые ученые». Вып.16. 2020

13. Лейкина Д.Д. Семантические поля и их взаимодействие с контекстуальными образованиями в речи. Сборник научных статей филологического ф-та Дальневосточного Государственного Университета. Серия «Наука России». Вып.20. 2020

14. Пауль В.К. Идиоматика как основа существования языковых структур. Сборник научных статей Вильнюсского Университета. «Филология и педагогика». Вып.35. 2020

15. Раудонис В. Язык и его структуры. Эстония. Тартусский Университет. Записки факультета лингвистики. Вып.22. 2020

16. Рахман Дж. Методическое обоснование преподавания устной речи в летних языковых школах Великобритании. Кембридж. Издание Кембриджского Университета. Серия «Вспомогательные материалы для преподавателей английского языка». Изд.4. 1999

17. Черная А.И. Основные сложности обучения идиомам в Высшей школе. Научные записки филологического ф-та Псковского Государственного Университета. Вып.8. Псков. 2019

18. Штеженбах В.О. Фразеологичкие структуры в современных европейских языках. Сборник научных статей Вильнюсского Университета. «Филология и педагогика». Вып.8.Вильнюс. 2020 